\title{
Benign Paroxysmal Positional Vertigo
}

\author{
Seung-Han Lee, $\mathrm{MD}^{\mathrm{a}, \mathrm{c}}$; Ji Soo Kim, MD, $\mathrm{PhD}^{\mathrm{b}}$ \\ Department of ${ }^{a}$ Neurology, Chonnam National University Medical School, Gwangju, Korea \\ Department of ${ }^{b}$ Neurology, Seoul National University Bundang Hospital, Seoul National University College of Medicine, Seongnam, Korea \\ Department of ${ }^{\mathrm{C}}$ Neurology, Johns Hopkins University School of Medicine, Baltimore, USA
}

\author{
Received February 13, 2010 \\ Revised March 8, 2010 \\ Accepted March 9, 2010
}

\section{Correspondence \\ Ji Soo Kim, MD, PhD \\ Department of Neurology, \\ Seoul National University \\ Bundang Hospital, \\ Seoul National University \\ College of Medicine, \\ 166 Gumi-ro, Bundang-gu, \\ Seongnam 463-707, Korea \\ Tel +82-31-787-7463 \\ Fax +82-31-719-6828 \\ E-mail jisookim@snu.ac.kr}

Benign paroxysmal positional vertigo (BPPV) is characterized by brief recurrent episodes of vertigo triggered by changes in head position. BPPV is the most common etiology of recurrent vertigo and is caused by abnormal stimulation of the cupula by free-floating otoliths (canalolithiasis) or otoliths that have adhered to the cupula (cupulolithiasis) within any of the three semicircular canals. Typical symptoms and signs of BPPV are evoked when the head is positioned so that the plane of the affected semicircular canal is spatially vertical and thus aligned with gravity. Paroxysm of vertigo and nystagmus develops after a brief latency during the Dix-Hallpike maneuver in posterior-canal BPPV, and during the supine roll test in horizontal-canal BPPV. Positioning the head in the opposite direction usually reverses the direction of the nystagmus. The duration, frequency, and symptom intensity of BPPV vary depending on the involved canals and the location of otolithic debris. Spontaneous recovery may be expected even with conservative treatments. However, canalithrepositioning maneuvers usually provide an immediate resolution of symptoms by clearing the canaliths from the semicircular canal into the vestibule.

J Clin Neurol 2010;6:51-63

Key Words vertigo, nystagmus, benign paroxysmal positional vertigo, canalith-repositioning maneuver.

\section{Introduction}

Benign paroxysmal positional vertigo (BPPV) is one of the most common disorders causing dizziness. ${ }^{1,2}$ Up to $90 \%$ of positioning vertigo/nystagmus cases are attributable to $\mathrm{BPPV},{ }^{3}$ which has been recognized as a clinical entity since the late 1800s and early 1900s. ${ }^{4}$ In 1921, Barany described the characteristic nystagmus and vertigo induced by position change and attributed these symptoms to a disorder of the otolithic organ. ${ }^{5}$ In 1952, Dix and Hallpike described torsional vertical nystagmus provoked by a specific ear-down position with a latency of several seconds, in which the nystagmus lasted only for a limited time (usually less than 20 seconds) and the direction of the nystagmus reversed on resuming the upright position. The nystagmus also showed a fatigability with a progressive decline of intensity on repetition of the maneuvers. ${ }^{6}$ These authors coined the term "benign paroxysmal positional vertigo", and the provocative positional testing was named in their honor.

Schucknecht was the first to provide a pathophysiological concept of BPPV. In 1969 he proposed the theory of "cupulo- lithiasis" on the basis of pathological studies that demonstrated otolithic debris attached to the cupula. ${ }^{7}$ According to the theory, the cupula, which became heavy due to attached otolithic debris, could be deflected by position changes, thus evoking nystagmus. ${ }^{7}$ However, the concept of cupulolithiasis has several limitations and is thus unable to explain all of the characteristics of nystagmus and vertigo in BPPV. In 1979, Hall proposed the concept of "canalolithiasis", which states that otolithic debris from the utricular macule migrates into the semicircular canal via the nonampullary portion, causing vertigo and nystagmus by moving freely inside the semicircular canal and inducing endolymph flow during positional changes. ${ }^{8}$ The concept of canalolithiasis was supported by the intraoperative observation of abundant free-floating debris in the endolymph of the posterior semicircular canal. ${ }^{9}$ This concept formed the theoretical basis of the canalith repositioning maneuvers (CRMs) to treat BPPV. ${ }^{10,11}$

Prior to the 1980s it was believed that BPPV developed only in the posterior semicircular canal. However, in 1985 the concept and clinical features of BPPV involving the horizontal semicircular canal (HC-BPPV) was introduced by Mc- 
Clure, who described seven cases with geotropic nystagmus (nystagmus beating toward the ground) during the Dix-Hallpike maneuver without any evidence of central lesions. ${ }^{12}$ Later, the apogeotropic type of BPPV was also reported, in which the nystagmus beats toward the ceiling during lateral head turning in the supine position. ${ }^{13}$

Torsional downbeat nystagmus during straight head hanging $(\mathrm{SHH})$ or Dix-Hallpike maneuvers has also been ascribed to BPPV involving the anterior canal (AC-BPPV) when there are no central pathologies. ${ }^{14}$ However, the existence of ACBPPV has been challenged by others. ${ }^{15}$

\section{Symptoms of BPPV}

The main symptom of BPPV is vertigo (spinning sensation) induced by a change in head position with respect to gravity. Patients typically develop vertigo when getting out of bed, rolling over in bed, tilting their head back, for example to look up shelves, or bending forward, for example when fastening their shoes. However, the symptoms of BPPV may vary among patients, and may manifest with nonspecific dizziness, postural instability, lightheadedness, and nausea. ${ }^{16,17}$ The vertigo in BPPV is typically intermittent and positioning dependent. Patients with BPPV do not experience severe vertigo during usual daytime activities performed with an upright posture, but rather when they get out of bed.

The vertigo is mostly transient in BPPV, its duration correlating well with the duration of the positioning nystagmus, which usually resolves within 30 seconds in posterior canal BPPV (PC-BPPV). ${ }^{6}$ However, the duration is relatively longer (sometimes lasting longer than 1 minute) in HC-BPPV. ${ }^{18}$ Even though patients with BPPV occasionally report persistent dizziness and imbalance, careful history taking reveals that in most cases, aggravation of their symptoms occurs with position change.

\section{Epidemiology}

There is a dearth of epidemiologic studies on BPPV. The prevalence of BPPV has been reported as 10. 7-64 per 100,000 population. ${ }^{19}$ According to a recent study in Germany in which utilized telephone-based interviewing, the lifetime prevalence of BPPV is $2.4 \%$, with a 1 -year-incidence of $0.6 \%{ }^{20}$

Idiopathic BPPV is more prevalent in the elderly and in women, ${ }^{20,21}$ with a women-to-men ratio of 2-3:1 and a peak age at onset in the sixth decade of life. ${ }^{21} \mathrm{BPPV}$ is more likely to involve the right ear, a factor that may be related to the habit of sleeping on the right side in the general population. ${ }^{22}$

BPPV mostly develops in the posterior and horizontal semicircular canals. ${ }^{23}$ PC-BPPV has been said to account for 60 -
$90 \%$ of all BPPV cases, and HC-BPPV for $5-30 \%$ of the cases. ${ }^{23,24}$ However, HC-BPPV now appears to be more prevalent than was previously thought. ${ }^{23-25}$ The proportion of HC-BP$\mathrm{PV}$-attributable cases decreases with increasing mean time interval from the symptom onset to diagnosis, ${ }^{24,26}$ probably due to the higher rate of spontaneous resolution in HC-BPPV. Thus, the relative proportion of each type of BPPV may depend upon the setting of each clinic. BPPV rarely involves the anterior semicircular canal. ${ }^{14}$ BPPV arising from multiple canals has also been described. ${ }^{24,27}$

\section{Causes}

The cause of BPPV is mostly unknown (idiopathic). In view of the high prevalence of BPPV in middle-aged women, hormonal factors may play a role in the development of BPPV. ${ }^{28}$ In a recent study, bone mineral density score was decreased in both women and men with idiopathic BPPV compared with that in normal controls without a history of dizziness. ${ }^{29}$ The prevalence rates of osteopenia $(-2.5<\mathrm{T}$-score $<-1.0)$ and osteoporosis (T-score $\leq-2.5$ ) were also found to be higher in both women and men with BPPV than in normal controls. Furthermore, in women aged $\geq 45$ years, the lowest T-scores were also decreased in the recurrent group, compared with those in the de novo group. These findings suggest the involvement of deranged calcium metabolism in idiopathic BPPV and a significant association between osteopenia/osteoporosis and idiopathic BPPV. Otoconia are deposits of calcium carbonate in the form of composite calcite crystals, and bone contains $99 \%$ of the calcium found in the body. ${ }^{29}$ Decreased estrogen levels may disturb the internal structure of the otoconia or their interconnections and attachments to the gelatinous matrix. Alternatively, an increase in the concentration of free calcium in the endolymph due to increased calcium resorption may reduce the capacity to dissolve the dislodged otoconia. ${ }^{28}$

BPPV may develop secondary to various disorders that damage the inner ear and detach the otolith from the utricular macule..$^{21,30-32}$ Head trauma causing mechanical damage to the ear is the most common cause of BPPV. ${ }^{32}$ Patients rarely develop BPPV after mastoid surgery or if they engage in a persistent head-tilt position, such as among barbers or dentists. ${ }^{33,34}$

Compared with the idiopathic form, traumatic BPPV exhibits several distinctive characteristics, including a higher incidence of bilaterality, involvement of multiple canals on the same side, equal occurrence among women and men, a younger and more even age distribution, more difficult to treat, and frequent recurrences. ${ }^{31,32}$ In addition, BPPV may develop secondary to any of the inner ear diseases (e.g., vestibular neuritis, labyrinthitis, and Meniere's disease) that give rise to degeneration and detachment of the otoconia, but do not totally 
impair semicircular canal function. ${ }^{30}$ The incidence of BPPV is also known to be higher in patients who suffer from migraine, even though the exact mechanism remains to be elucidated. ${ }^{35}$ BPPV has been reported to occur in association with giant-cell arteritis, diabetes, and hyperuricemia. ${ }^{36-38}$

\section{Pathomechanism}

The detached otolith debris could be either attached to the cupula (cupulolithiasis) or may be free-floating in the semicircular canals (canalolithiasis) (Fig. 1). Pathological studies have shown that both of these conditions exist. ${ }^{7}$ The otolithic debris deflects the cupula and gives rise to a spinning sensation via a direct gravitational effect on the cupula or by inducing endolymph flow during head motion in the direction of gravity (Fig. 2). According to the cupulolithiasis theory, a cupular deposit (heavy cupula) would induce a gravitational effect on the crista. However, the action of free-floating debris is the currently accepted pathophysiologic mechanism of typical BPPV. According to the canalolithiasis theory, the free-floating particles move under the influence of gravity when changing the position of the canal in the earth-vertical plane. The hydrodynamic drag of the particles induces endolymphatic flow, resulting in cupular displacement and leading to the observed typical responses. ${ }^{9}$
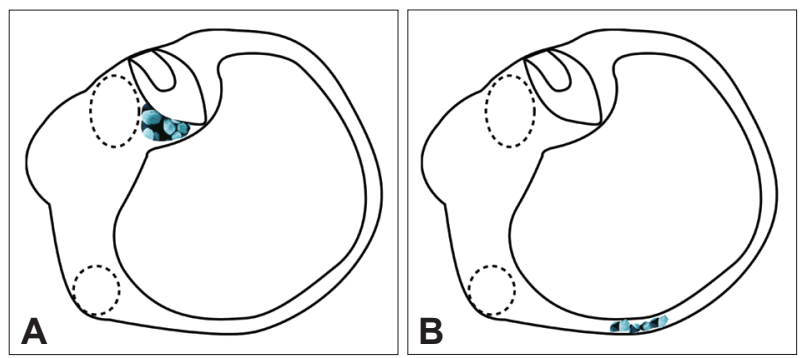

Fig. 1. Mechanism of benign paroxysmal positional vertigo (BPPV). The detached otolith debris may be attached to the cupula (A: $\mathrm{Cu}$ pulolithiasis) or free-floating in the semicircular canals (B: Canalolithiasis).

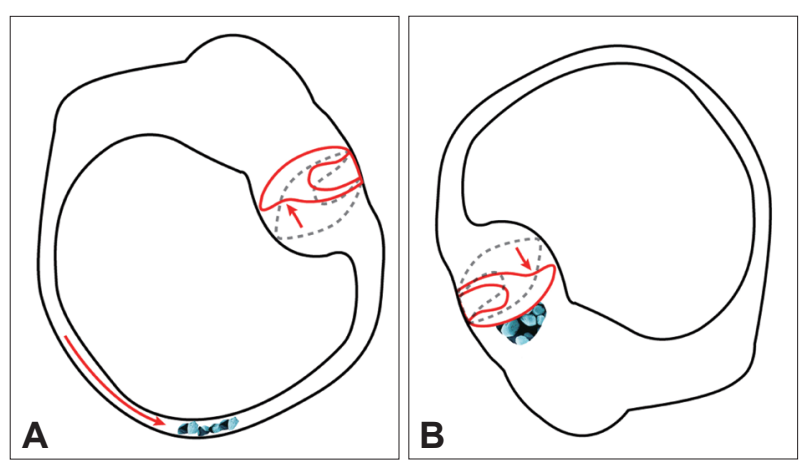

Fig. 2. Deflection of the cupula due to either endolymphatic flow induced by a hydrodynamic drag of the particles (A: Canalolithiasis) or a direct gravitational effect of the otolithic debris (B: Cupulolithiasis).
Several studies have attempted to determine utricular (otolithic) abnormalities in BPPV, but they have produced inconsistent results. ${ }^{39-42}$ Patients with BPPV may exhibit abnormalities in vestibular evoked myogenic potentials, subjective visual horizontal, and gain during off-vertical axis rotation. ${ }^{40-42}$

\section{Diagnosis}

Each type of BPPV is diagnosed by observing the patterns of nystagmus induced during positioning maneuvers that have been designed to move only the involved canal in the direction of maximal gravity. However, accurate observations of the nystagmus require the fixation to be removed during the maneuvers.

\section{PC-BPPV}

In PC-BPPV, the positioning nystagmus is typically induced
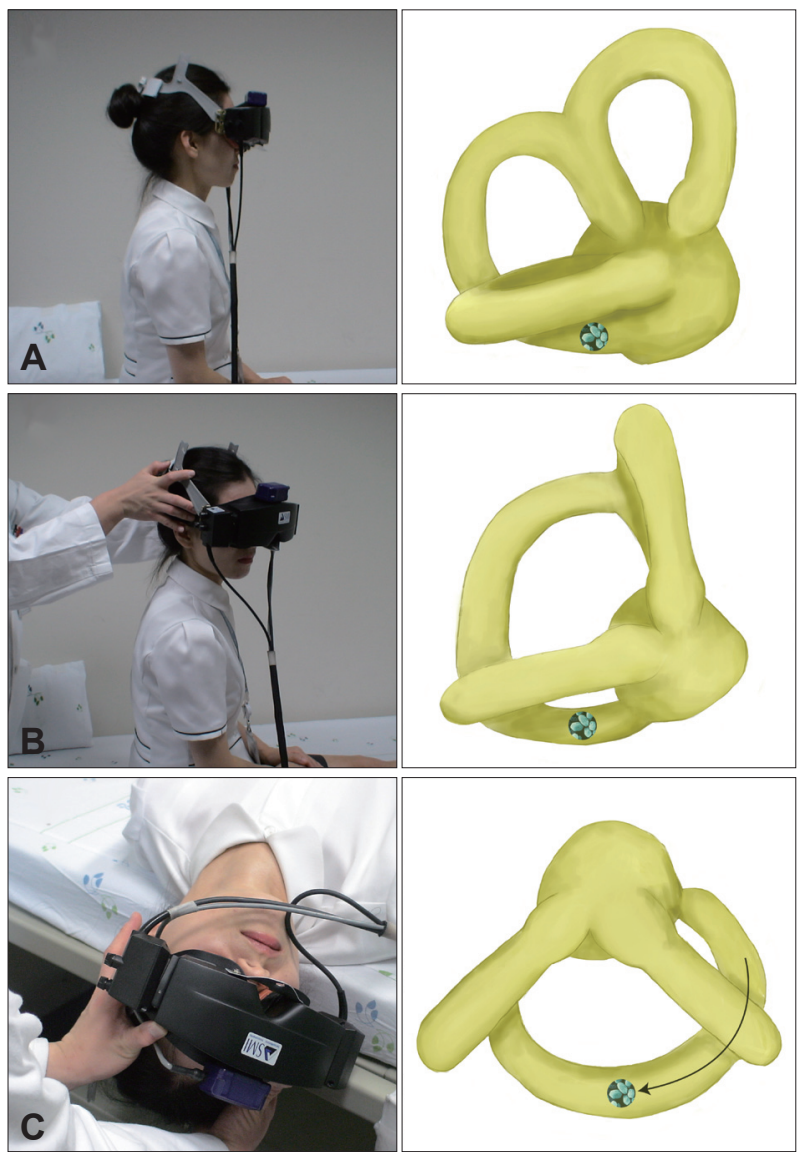

Fig. 3. Dix-Hallpike maneuver for the diagnosis of BPPV involving the right posterior semicircular canal (right PC-BPPV). After seating the patient upright $(A)$, the head is turned $45^{\circ}$ in the direction of the involved ear (B: right ear in this figure). The patient is then moved from the sitting to the supine position, ending with the head hanging at $20^{\circ}$ off the end of the examination table (C). The corresponding illustrations demonstrate the orientation of the semicircular canals and location of the otolithic debris in the posterior canal (viewed from the patient's right side). BPPV: benign paroxysmal positional vertigo. 
by Dix-Hallpike maneuvers in the direction of the involved canal (Fig. 3) ${ }^{6,21}$ During the Dix-Hallpike maneuver, it is thought that the free-floating otolithic debris (canalolithiasis) in the posterior canal moves away from the cupula and stimulates the posterior canal by inducing ampullofugal flow of the endolymph (Ewald's first law). Excitation of the posterior canal in turn activates the ipsilateral superior oblique and contralateral inferior rectus muscles, which results in tonic downward deviation of the eyes with a torsion in the direction of the uppermost ear. Accordingly, the resultant nystagmus would be upbeating and torsional, with the upper pole of the eyes beating toward the lowermost ear. The nystagmus usually develops with a brief latency of several seconds, resolves within 1 minute (usually within 30 seconds), and its direction is reversed on sitting. ${ }^{6}$ The nystagmus diminishes (i.e., it fatigues) with repeated examinations. ${ }^{6}$ Cupulolithiasis may exist in the posterior canal. Compared with canalolithiasis, the cupulolithiatic type of PC-BPPV tends to have shorter latency and longer time constant (i.e., it is more persistent). ${ }^{43}$

The Dix-Hallpike maneuver has been considered the gold standard for diagnosing PC-BPPV. However, this maneuver should be performed with caution in patients with a history of neck surgery, cervical radiculopathy, and vascular dissection syndrome, since it requires rotation and extension of the neck during the positioning. ${ }^{44}$ The side-lying test may be used as an alternative when the Dix-Hallpike maneuver is inapplicable; after seating the patient on the side of an examination couch, the patient quickly lies down on the side with the head turned to $45^{\circ}$ in the opposite direction (Fig. 4). ${ }^{44}$

\section{HC-BPPV}

HC-BPPV is diagnosed by the supine roll test (the Pagnini-
McClure maneuver), in which the head is turned by about $90^{\circ}$ to each side while supine (Fig. 5). During this maneuver, horizontal nystagmus may beat toward the ground (geotropic nystagmus)(Fig. 5A) or toward the ceiling (apogeotropic nystagmus)(Fig. 5B). The induced nystagmus tends to be more persistent in HC-BPPV than in PC-BPPV. The nystagmus evoked during positioning in HC-BPPV usually exhibits less fatigability and a shorter latency than that evoked in PC-BPPV. ${ }^{18}$

Determination of the involved side (lateralization) is very important for the proper treatment of HC-BPPV using CRMs, which is discussed later (Table 1). Since ampullopetal flow of the endolymph evokes a greater response than ampullofugal flow in the horizontal canal (Ewald's second law), the induced nystagmus is stronger when the head is turned toward the affected ear in the geotropic type of HC-BPPV. In contrast, head turning to the healthy ear generates a stronger nystagmus in apogeotropic HC-BPPV. ${ }^{45-48}$ Determination of the involved ear is sometimes difficult due to rather symmetrical responses, especially if the induced nystagmus is not recorded. In these instances, other findings may provide clues toward determining the affected ear. In HC-BPPV, nystagmus may be induced by lying supine from the sitting position [lying-down nystagmus (LDN)] or by bending the head forward while sitting [head-bending nystagmus (HBN)] ${ }^{46-48}$ In up to $80 \%$ of HC-BPPV cases, LDN and HBN are in the opposite direction. In geotropic HC-BPPV, HBN beats mostly toward the affected ear, while LDN is directed mostly toward the healthy ear. ${ }^{46-48} \mathrm{HBN}$ in geotropic $\mathrm{HC}-\mathrm{BPPV}$ is ascribed to ampullopetal migration of the otoliths, while LDN is explained by ampullofugal displacement of the otoliths in the horizontal canal. In contrast, HBN is mostly contralesional and LDN is usually ipsilesional when observed in apogeotropic HC-

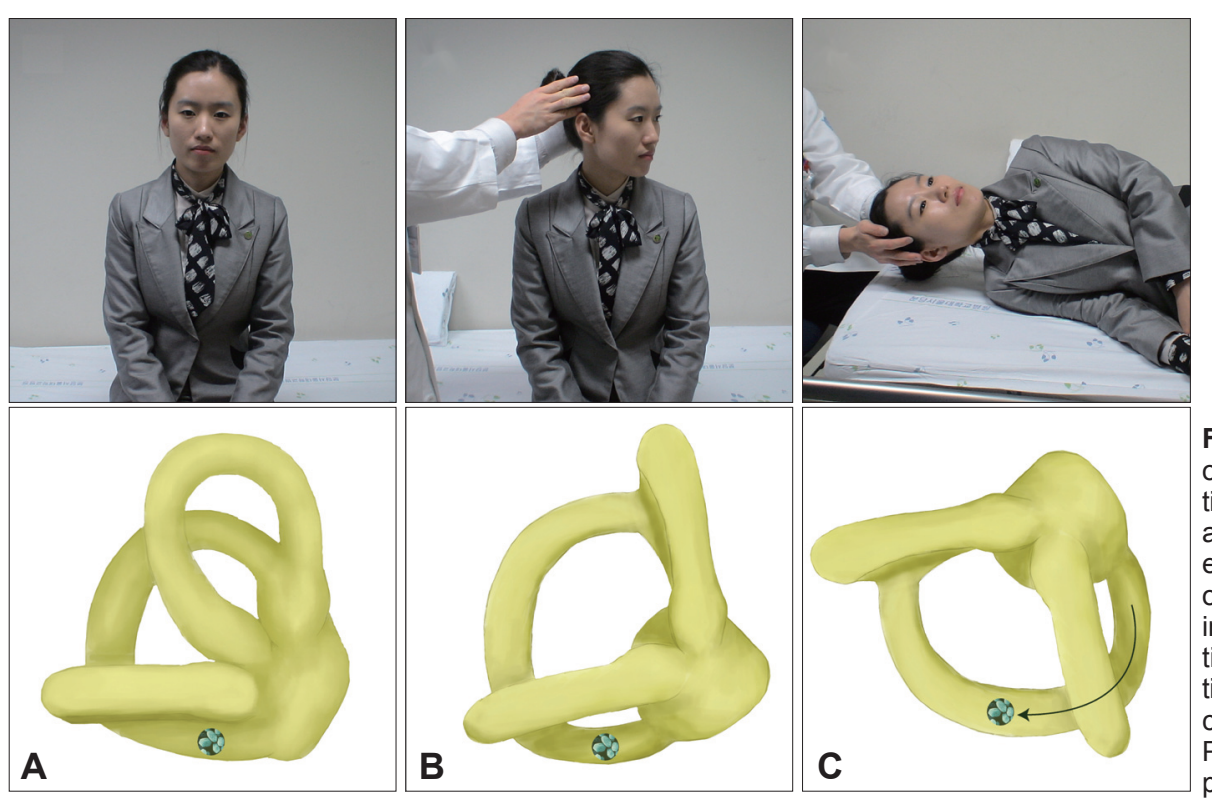

Fig. 4. Side-lying test for the diagnosis of right PC-BPPV. After seating the patient on the examination table $(A)$, the head is turned $45^{\circ}$ away from the involved ear (B). The patient then lies on the side of the involved ear (C). The corresponding illustrations demonstrate the orientation of the semicircular canals and location of the otolithic debris in the posterior canal (viewed from the front). PC-BPPV: posterior canal benign paroxysmal positional vertigo. 

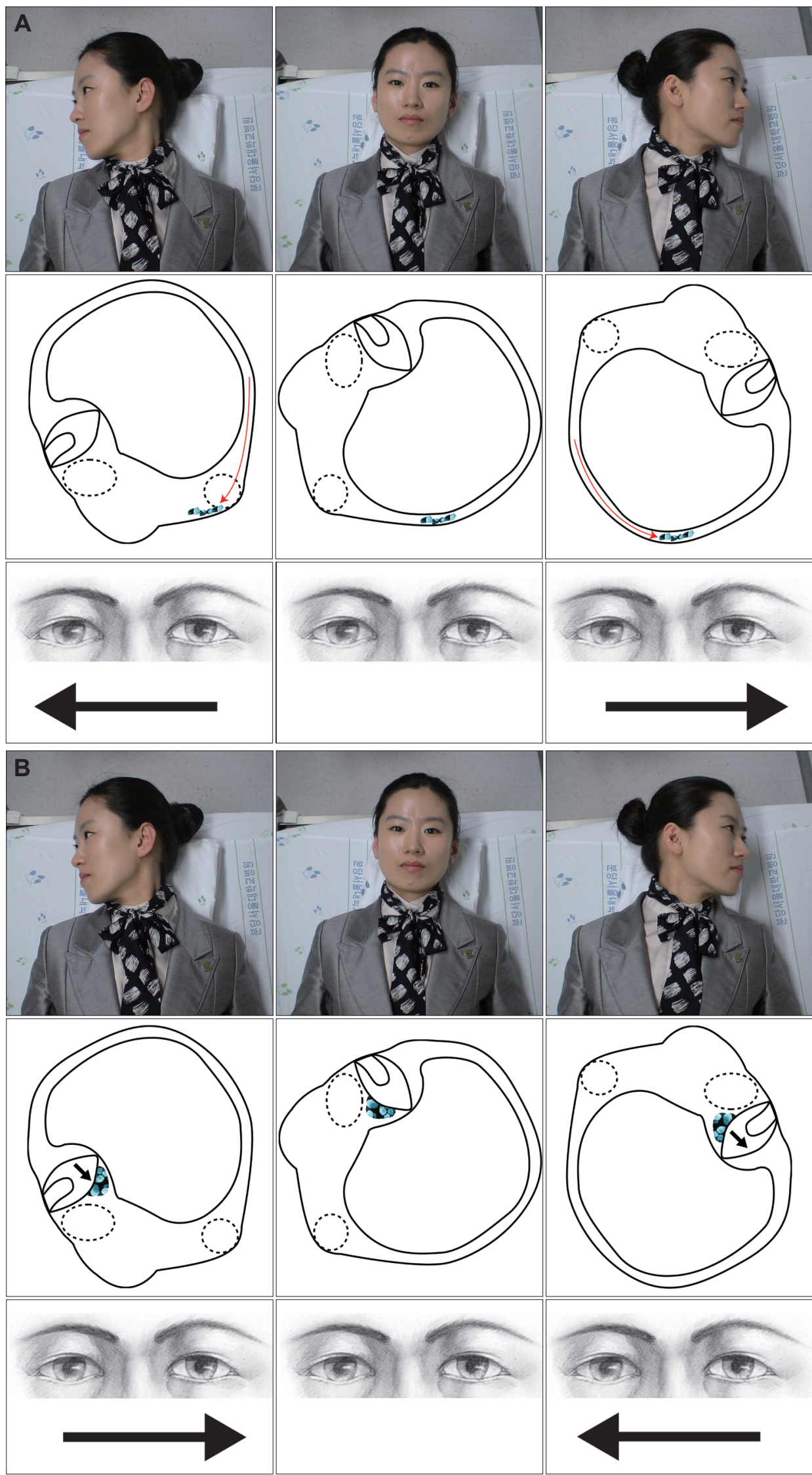

Fig. 5. Supine roll test (Pagnini-McClure maneuver) for the diagnosis of BPPV involving the horizontal semicircular canal (right HC-BPPV). The head is turned about $90^{\circ}$ to each side while supine. A: Canalolithiasis. B: Cupulolithiasis. The corresponding illustrations demonstrate the location of the otolithic debris in the horizontal canal during each maneuver, and the direction of the induced nystagmus (arrows). BPPV: benign paroxysmal positional vertigo. 
Table 1. Lateralization of horizontal canal benign paroxysmal positional vertigo (HC-BPPV), based upon the direction and intensity of nystagmus

\begin{tabular}{lll}
\hline & \multicolumn{2}{c}{ Lateralization of the lesion side of HC-BPPV } \\
\cline { 2 - 3 } & \multicolumn{1}{c}{ Geotropic nystagmus } & Apogeotropic nystagmus \\
\hline Intensity of nystagmus (Ewald's second law) & Stronger side & Weaker side \\
Lying-down nystagmus (sitting to supine position) & Usually contralesional & Usually ipsilesional \\
Head-bending nystagmus (bending the head forward) & Usually ipsilesional & Usually contralesional \\
Reversal of initial nystagmus & Possibly occurs ipsilesionally* & Uncommon \\
Null point (during head turning, $10-20^{\circ}$ ) & Uncommon, ${ }^{95}$ but laterality is uncertain & Usually present on lesion side \\
\hline
\end{tabular}

*The maximal slow phase velocity of the initial geotropic nystagmus is usually greater than $100 \%$ second.

$\mathrm{BPPV}^{48} \mathrm{HBN}$ and LDN in apogeotropic HC-BPPV are explained by deflection of the heavy cupula in response to the positional change.

In apogeotropic HC-BPPV, the induced horizontal nystagmus may disappear when the head is turned to the affected ear by $10-20^{\circ}$, while supine (null point). ${ }^{49}$ The null point is explained by alignment of the heavy cupula in the direction of the gravitational vector.

Spontaneous nystagmus, also known as pseudospontaneous nystagmus, ${ }^{50}$ is not uncommon in HC-BPPV. In previous reports, $66-76 \%$ of HC-BPPV patients exhibited spontaneous nystagmus. ${ }^{45,50}$ The spontaneous nystagmus in HC-BPPV may be related to the anatomical position of the horizontal semicircular canal, which is inclined $30^{\circ}$ backwards from the horizontal plane. ${ }^{50}$ Accordingly, the gravitational force may affect the otolithic debris inside the canal or the heavy cupula, even when in the upright sitting position. For the same reason, pseudospontaneous nystagmus disappears when the patient's head is bent forwards by about $30^{\circ}$. In this position, since the horizontal canal is aligned with respect to the earthhorizontal plane, the effect of gravity is negated. ${ }^{49,50}$ However, pseudospontaneous nystagmus should be differentiated from continuous nystagmus with sustained vertigo resulting from so-called canalith jam and negative endolymph pressure between the plug and the cupula. ${ }^{51}$

In BPPV, spontaneous reversal of the initial positioning nystagmus rarely occurs without further position changes. In geotropic HC-BPPV, the initial geotropic nystagmus occasionally reverses its direction when the head is turned toward the lesion side, and the induced nystagmus is intense (maximal slow phase velocity $=104 \pm 62 \%$ second, mean \pm SD) ${ }^{52}$ Short-term adaptation of the vestibulo-ocular reflex seems to be the main mechanism underlying this spontaneous reversal of the initial positioning nystagmus. ${ }^{25,52}$

\section{AC-BPPV}

BPPV rarely involves the anterior semicircular canal, and AC-BPPV exhibits several characteristics that contrast with those of PC-BPPV. In AC-BPPV, SHH as well as the DixHallpike maneuver on either side may evoke downbeat nys- tagmus with an ipsitorsional (upper poles of the eyes beating toward the involved ear) component. ${ }^{53,54}$ Furthermore, the torsional nystagmus in AC-BPPV may not be evident, as it is in PC-BPPV.

\section{Mixed-canal type of BPPV}

BPPV may involve multiple semicircular canals. The mixedcanal type of BPPV, the most common of which is a combination of PC- and HC-BPPV, ${ }^{24}$ comprises about $1.5-5.0 \%$ of all BPPV cases in the literature. ${ }^{24,55}$ The mixed-canal type of BPPV frequently involves the canals on the same side (e.g., right horizontal and right posterior canals), ${ }^{27,55}$ but bilateral involvement has also been reported. ${ }^{18}$ Trauma may increase the risk of mixed-canal BPPV. ${ }^{55}$

\section{Differential Diagnosis}

Most BPPV patients worry that they may be suffering from a serious disorder, such as stroke. Even though BPPV is a benign and self-remitting disease, more serious disorders such as posterior circulation stroke can mimic BPPV. ${ }^{56}$ However, central positional nystagmus usually accompanies persistent vertigo, profound imbalance, and other neurological symptoms and signs (Table 2). ${ }^{57}$

Since positional downbeat nystagmus is a typical finding in lesions involving the cerebellum, ${ }^{58}$ and AC-BPPV is a rare condition, accounting for only $1.5-5 \%$ of all BPPV cases, a diagnosis of AC-BPPV should be reserved only for typical cases without other neurological deficits. ${ }^{24,58}$ Even in those patients, the possibility of central pathology should be investigated when repeated CRMs fail to resolve the symptoms and nystagmus.

In a previous study, $72 \%$ of patients with positional downbeat nystagmus exhibited central disorders, while 24\% (most of which were believed to be AC-BPPV) had unknown etiology without a central pathology. ${ }^{58}$

Rarely, central paroxysmal positional vertigo mimicking BPPV has been reported after infarction dorsolateral to the fourth ventricle ${ }^{56}$ or nodulus, ${ }^{59}$ or in a solitary plaque involving the brachium conjunctivum. ${ }^{60}$ 
Table 2. Clinical and differential features of benign paroxysmal positional vertigo (BPPV) versus central paroxysmal positional vertigo (CPPV)

\begin{tabular}{|c|c|c|}
\hline & BPPV & CPPV \\
\hline Latency & Usual (shorter in HC-BPPV) & Unusual \\
\hline Duration of attack & Usually less than 60 seconds (longer in HC-BPPV) & Variable, usually longer than BPPV \\
\hline Direction of nystagmus & $\begin{array}{l}\text { Torsional/vertical (PC/AC-BPPV) and horizontal } \\
\text { (HC-BPPV); compatible with the stimulated } \\
\text { canal plane }\end{array}$ & $\begin{array}{l}\text { Pure vertical (usually downbeat) or pure torsional; } \\
\text { not attributable to the stimulated canal plane; } \\
\text { possibly mimics BPPV pattern* }\end{array}$ \\
\hline Fatigability & Usual (possibly rare in HC-BPPV) & Unusual \\
\hline Nausea and vomiting & $\begin{array}{l}\text { Rare on single precipitating maneuver; not } \\
\text { uncommon after several maneuvers; usually } \\
\text { associated with intense nystagmus }\end{array}$ & $\begin{array}{l}\text { Frequent even on single precipitating maneuver; } \\
\text { not necessarily associated with intense nystagmus }\end{array}$ \\
\hline Mechanism & Debris moving in semicircular canal & Damage to central otolith-ocular pathways \\
\hline Natural course & $\begin{array}{l}\text { Spontaneous recovery within several weeks } \\
\text { in } 70-80 \%\end{array}$ & Spontaneous recovery within weeks possible \\
\hline $\begin{array}{l}\text { Associated neurological } \\
\text { signs and symptoms }\end{array}$ & None & $\begin{array}{l}\text { Often cerebellar and other oculomotor signs; } \\
\text { possibly none }\end{array}$ \\
\hline Brain imaging & Normal & $\begin{array}{l}\text { Cerebellar lesions (common in dorsal vermis, } \\
\text { nodulus, dorsolateral to the fourth ventricle); } \\
\text { cerebellar atrophy; craniocervical anomaly; } \\
\text { possibly normal (VBI) }\end{array}$ \\
\hline
\end{tabular}

*Apogeotropic nystagmus is common. Other BPPV patterns are also possible. AC: anterior canal, PC: posterior canal, VBI: vertebrobasilar insufficiency.

\section{Treatments}

BPPV is usually a self-remitting disorder and may resolve as time goes on without specific treatment. According to a report on the natural course of untreated BPPV, most HC-BPPVs resolve within $16 \pm 19$ days and PC-BPPVs within $39 \pm 47$ days of their onset. ${ }^{26}$ However, a correct diagnosis and proper repositioning maneuvers may allow a rapid and simple cure for the BPPV. ${ }^{61}$

By the 1970s, the treatment of BPPVs mostly involved the administration of vestibular suppressants and restriction of the position change responsible for the vertiginous spells, which meant that resolution of the condition was largely time consuming. After the Brandt-Daroff exercise was introduced in 1980 , it was usually recommended that patients with BPPV perform active exercises. ${ }^{62}$ By adopting the Brandt-Daroff exercise, the treatment period of BPPV was shortened by 10 14 days. However, the aim of this exercise was habituation and compensation of the vestibular system. ${ }^{62}$ Patients with BPPV were not treated effectively until the late 1980s and early 1990s, when CRMs were introduced.

\section{CRMs}

\section{PC-BPPV}

The most popular methods for treating PC-BPPV are Semont's liberatory and Epley's maneuvers. ${ }^{10,11}$ These maneuvers employ stepwise changes in head position (Fig. 6) to flush freefloating otolithic debris out of the semicircular canals and back into the utricle. The original version of Epley's maneu- ver has been modified by other physicians for ease and simplicity. The mastoid vibration originally applied during the repositioning maneuvers by Epley is no longer recommended. ${ }^{63,64}$ Initially, patients were instructed to maintain an upright position for 48 hours after the repositioning maneuver; however, such position restriction after treatment is not mandatory and can be simplified. ${ }^{65}$

Theoretically, positional vertigo may be resolved after repositioning the otolithic debris into the utricle with Epley's maneuver. The reported success rate is about $80 \%$ after one round of the repositioning maneuver; the success rate increases with repetition of this protocol. According to a recent meta-analysis of the modified Epley's maneuver for PC-BP$\mathrm{PV}$, the treatment demonstrated a symptom improvement rate four times greater, and a nystagmus resolution rate five times greater than the placebo group. ${ }^{66}$

The results of Epley's maneuver can be predicted even during the maneuver. When the head is turned $90^{\circ}$ toward the unaffected side after the Dix-Hallpike maneuver, the positioning nystagmus develops in the same direction as the maneuver (orthotropic nystagmus) if a clump of particulate matter moves in the correct direction into the common crus, resulting in a successful repositioning. However, the direction of the nystagmus would reverse if a heavy cupula with attached otolithic debris deflects ampullopetally or if the particles move back toward the cupula, which implies that the repositioning will be unsuccessful. ${ }^{67}$ Epley's maneuver is the only recommended method of treating PC-BPPV, with confirmed evidence level A according to the American Academy of Neurology. ${ }^{68}$ 


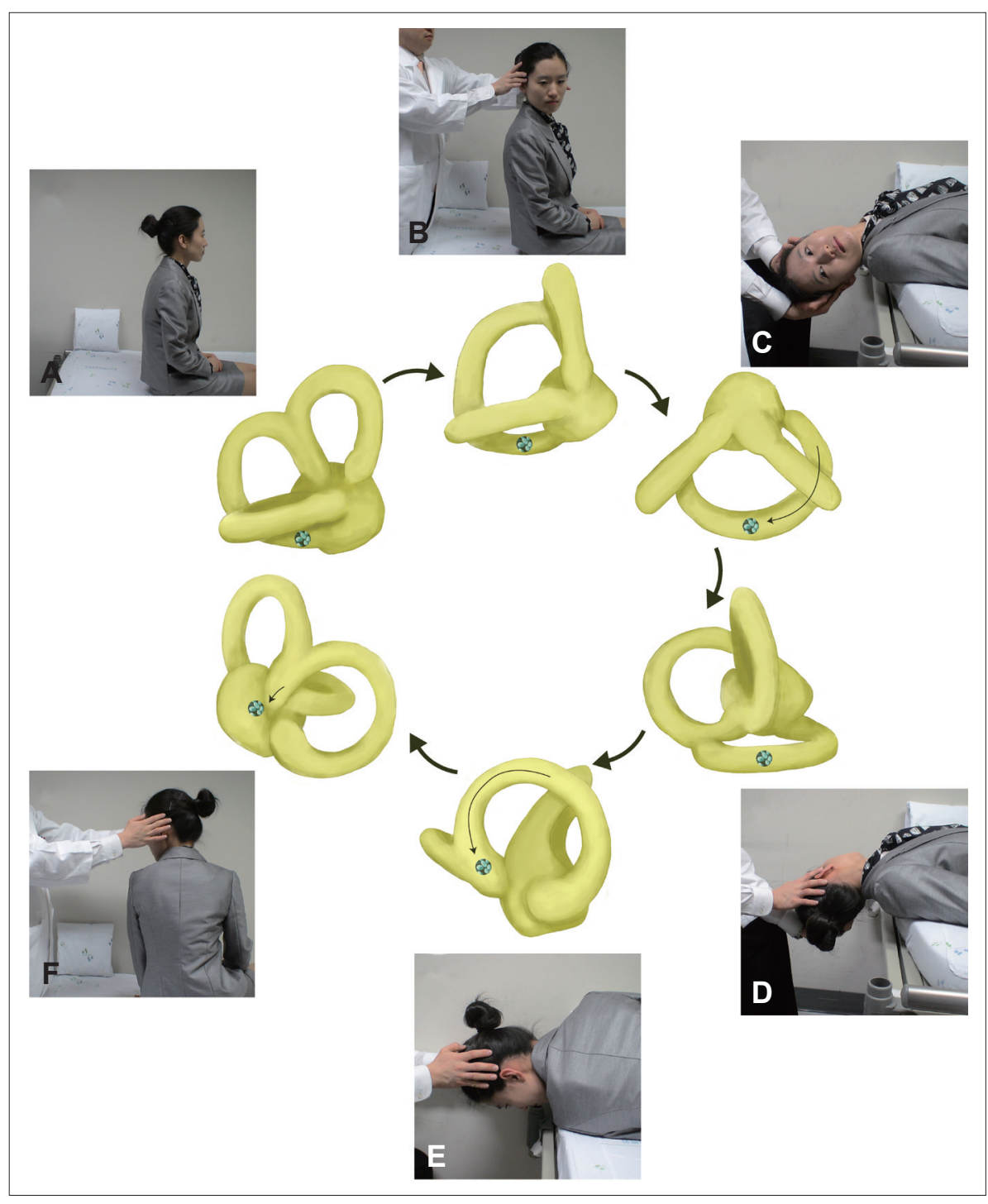

Fig. 6. Modified Epley's maneuver for the treatment of right PC-BPPV. After the DixHallpike maneuver $(A-C)$ for right $P C$ BPPV, the head is turned $90^{\circ}$ toward the unaffected ear (D) and the head and trunk continue turning another $90^{\circ}$ in the same direction $(E)$. The patient is then moved to the sitting position (F). Each position should be maintained for at least 1 or 2 minutes, or until the induced nystagmus and vertigo are resolved. The corresponding illustrations demonstrate the orientation of the semicircular canals and location of the otolithic debris in the posterior canal (viewed from the camera angle). PC-BPPV: posterior canal benign paroxysmal positional vertigo.
Semont's liberatory maneuver is also helpful in treating PC-BPPV (Fig. 7), ${ }^{69}$ and may be considered an alternative treatment modality for this condition, especially in patients who have difficulty extending the neck due to spinal disorders. However, the efficacy of Semont's liberatory maneuver has yet to be established unequivocally. ${ }^{68}$ Recently, a protocol for the self-treatment for PC-BPPV has been introduced based on Epley's and Semont's maneuvers. ${ }^{70,71}$ After diagnosis by a physician, a treatment maneuver is described to the patient that can be easily performed away from the hospital.

\section{Geotropic HC-BPPV}

Rotations of $270^{\circ}$ or $360^{\circ}$ around the yaw axis (the so-called barbecue maneuver) toward the unaffected ear are popular methods for the treatment of geotropic HC-BPPV. ${ }^{72}$ These maneuvers consist of sequential head turning of $90^{\circ}$ toward the healthy side while supine (Fig. 8). With these maneuvers, the free-floating otoconial debris migrates in the ampullofugal direction, finally entering the utricle through the nonampullated end of the horizontal canal.

Lying with the healthy ear downward for approximately 12 hours (forced prolonged position) can be employed, especially in patients suffering from severe symptoms who cannot perform sequential position changes. ${ }^{73}$ The Gufoni maneuver is another alternative. ${ }^{74-76}$ After being seated on an examination couch, the patient lies down on the healthy lateral side with a quick lateral movement and is maintained in this position for 1-2 minutes until resolution of the evoked nystagmus. A quick $45^{\circ}$ rotation of the head toward the floor is then performed, with the patient maintaining this position for another 2 minutes, followed by a slow return back to the starting position. A major advantage of the Gufoni maneuver is its simplicity.

\section{Apogeotropic HC-BPV}

Apogeotropic HC-BPPV is attributed to either cupulolithia- 

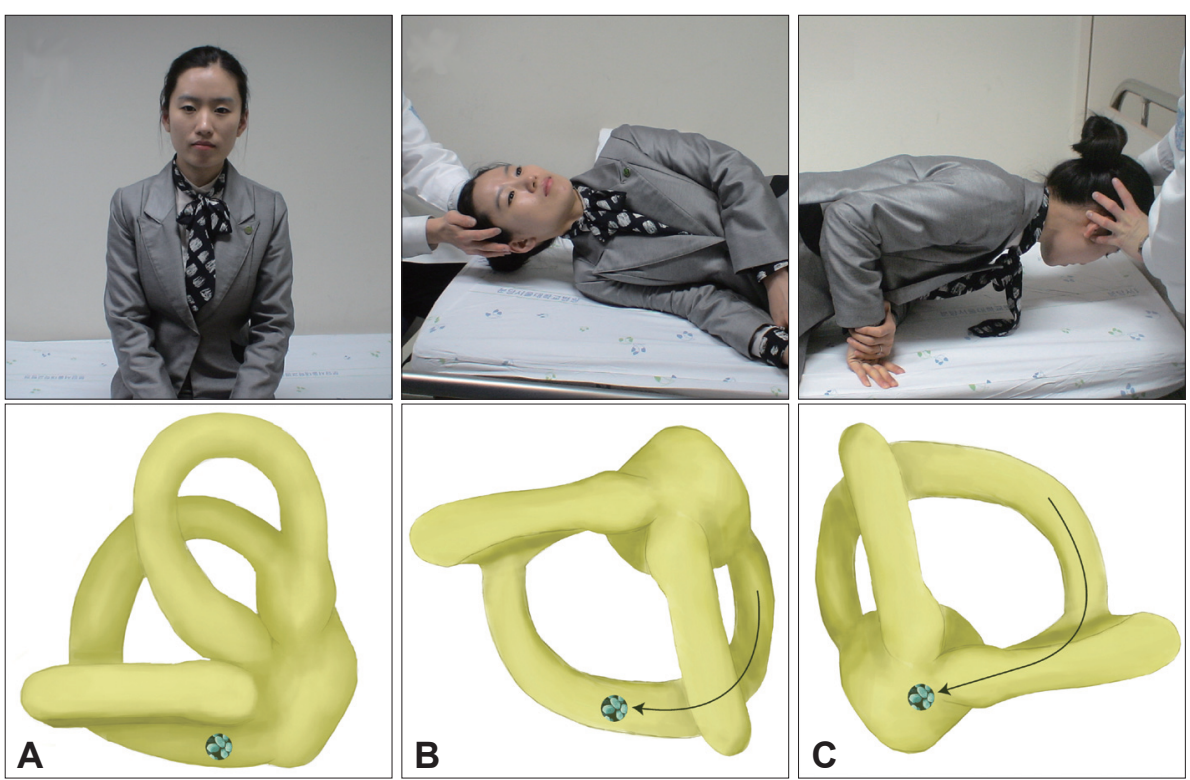

Fig. 7. Semont maneuver for the treatment of right PC-BPPV. After being seated on the examination table (A), the patient is rapidly moved into the side-lying position to the affected side after the head is turned $45^{\circ}$ to the unaffected side (B). The patient is then rapidly taken to the opposite side-lying position through the seated position without pausing (C). The head should be rotated toward the unaffected side throughout these movements. Finally, the patient is returned to a seated position. Each position should be maintained for at least 1 or 2 minutes, or until the induced nystagmus and vertigo are resolved. The corresponding illustrations demonstrate the orientation of the semicircular canals and location of the otolithic debris in the posterior canal (viewed from the camera angle). PC-BPPV: posterior canal benign paroxysmal positional vertigo. sis or canalolithiasis within the anterior arm of the horizontal semicircular canal. ${ }^{13,25}$ These explanations are consistent with the characteristics of the positioning nystagmus observed in HC-BPPV. In apogeotropic HC-BPPV, the therapeutic goal should be to detach the otolithic debris from the cupula or shift the debris from the anterior into the posterior arm of the horizontal canal. ${ }^{77}$

If the otolithic debris is attached at the utricular side of cupula, its detachment should result in immediate resolution of the positional vertigo and nystagmus. In the case of adhesion from the canal side of the cupula or free-floating particles in the anterior arm, detachment and shifting of the otolithic debris into the posterior arm would give rise to a transition into geotropic HC-BPPV. ${ }^{78}$ Therapeutic head-shaking in the horizontal plane, ${ }^{73,77}$ a modified Semont maneuver, ${ }^{79}$ and the Gufoni method ${ }^{80}$ have been proposed as treatment regimens for apogeotropic HC-BPPV.

The aim of head-shaking is to detach the otolithic debris from the cupula, irrespective of the side to which it is attached, using alternate accelerating and decelerating power. ${ }^{77}$

The modified Semont maneuver comprises the following three steps: ${ }^{79} 1$ ) the patient is brought briskly into a side-lying position with the affected ear downward; 2) the patient's head is turned $45^{\circ}$ downward, with this position being maintained for 2-3 min; and 3) the patient resumes the original sitting position. This maneuver was initially designed to dislodge the debris attached to the utricular side of the cupula. ${ }^{77,80}$

In the Gufoni maneuver for apogeotropic HC-BPPV, the patient sits with the head directed straight ahead and then quickly moves into a side-lying position on the affected side, remaining in this position for 1 or 2 more minutes after the end of apogeotropic nystagmus. The head is then turned $45^{\circ}$ upward very quickly and is kept in this position for 2 minutes, followed by a slow return to the sitting position. ${ }^{75,80}$ The Gufoni maneuver was designed to remove the otolithic debris from the anterior arm of the horizontal semicircular canal near the cupula.

A recent study adopting a prospective randomized trial found that the head-shaking maneuver was more effective than the modified Semont maneuver in treating apogeotropic HC-BPPV. ${ }^{77}$ However, the therapeutic efficacy of each maneuver should be determined by implementing a head-tohead comparison. ${ }^{68}$

\section{AC-BPPV}

Various repositioning maneuvers have also been advanced to treat AC-BPPV. In the reverse Epley maneuver, the patient submits to the same sequence of positional changes after the Dix-Hallpike maneuver on the side of the healthy ear. ${ }^{14}$ Modified repositioning maneuvers and forced prolonged position have also been adopted in treating this particular BPPV. ${ }^{81,82}$

\section{Rehabilitation}

Irrespective of the involved canals, the Brandt-Daroff exercise may be attempted when the repositioning maneuvers fail or if patients cannot tolerate the repositioning maneuvers (Fig. 9). ${ }^{62}$ The exercise may be repeated at liberty until resolution of the symptoms.

With respect to PC-BPPV, vestibular rehabilitation demonstrates superior treatment outcomes compared with placebo. ${ }^{83}$ However, vestibular rehabilitation is less effective than CRMs in producing complete symptom resolution. ${ }^{68}$ There are as yet insufficient data concerning the response of $\mathrm{HC}$ BPPV to vestibular rehabilitation. 


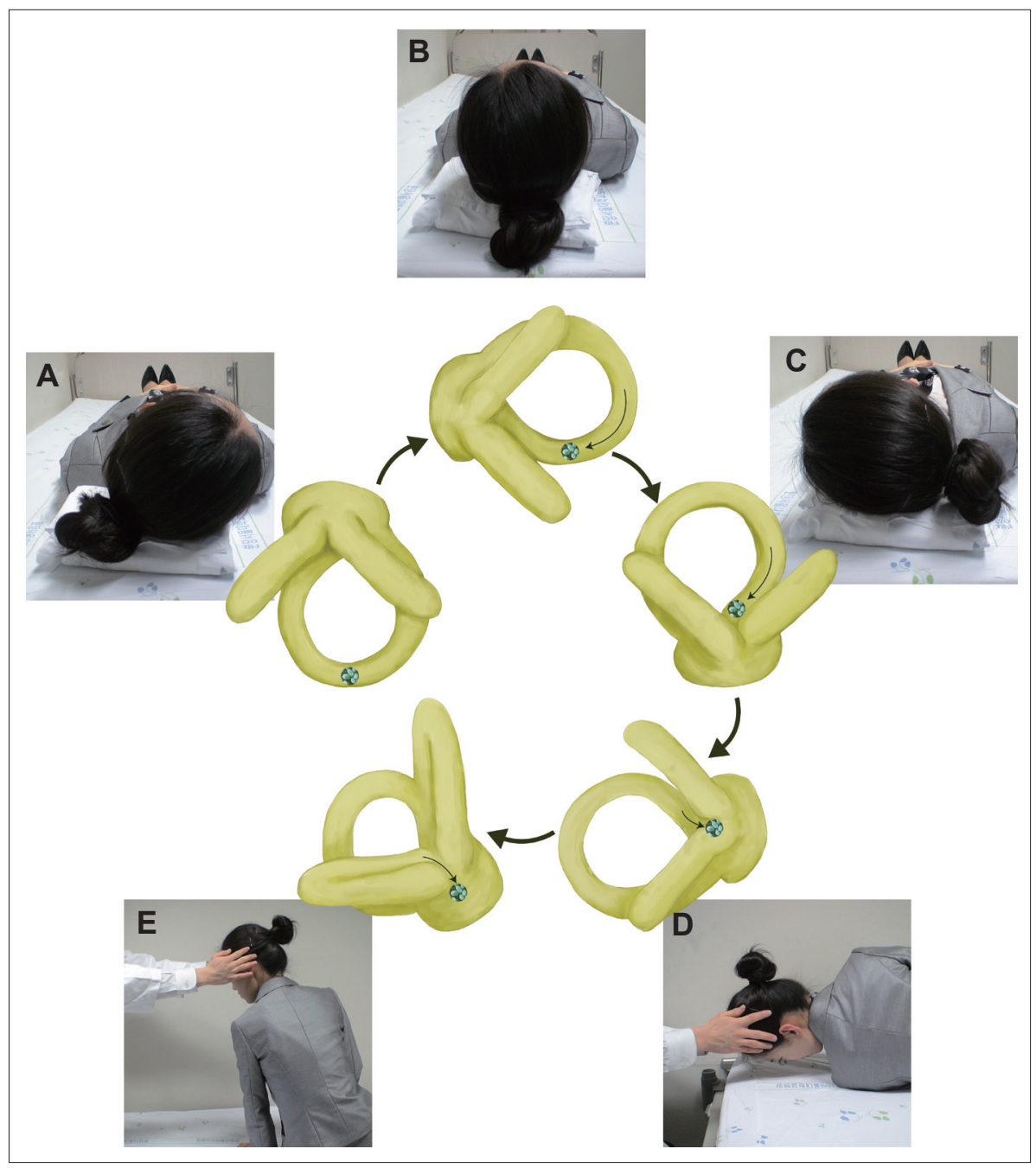

Fig. 8. Barbecue maneuver for the treatment of geotropic right HC-BPPV. After head turning toward the involved ear (A), the head is then turned $270^{\circ}$ toward the unaffected side through a series of stepwise $90^{\circ}$ turns (B-D) before resuming the sitting position (E). Each position should be maintained for at least 1 or 2 minutes, or until the induced nystagmus and vertigo are resolved. The corresponding illustrations demonstrate the orientation of the semicircular canals and the location of the otolithic debris in the horizontal canal. HC-BPPV: horizontal canal benign paroxysmal positional positional vertigo.
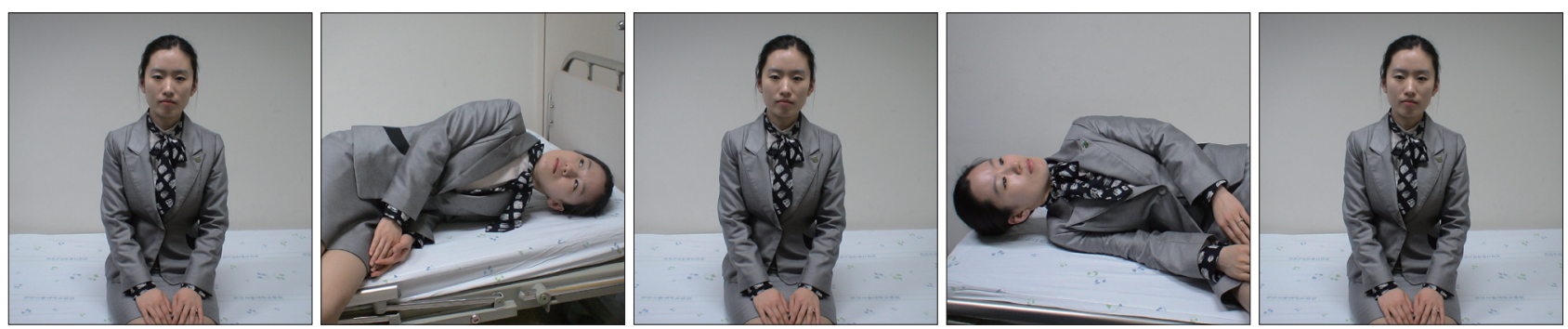

Fig. 9. Brandt-Daroff exercise. Patients are instructed to rapidly lie on their side, sit up, lie on the opposite side, and then again sit up. Each position should be maintained for at least 30 seconds. These exercises are repeated serially 5-10 times a day until resolution of the symptoms.

\section{Surgical treatment}

Even with repetitive CRMs and the Brandt-Daroff exercise, patients may suffer from persistent spells of disabling positioning vertigo or frequent recurrences that are refractory to repositioning maneuvers. Surgical treatments may be considered in these rare occasions of so-called intractable BPPV. ${ }^{84-87}$ Transection of the posterior ampullary nerve innervating the posterior canal (singular neurectomy) or posterior semicircular canal occlusion (canal plugging) have been performed for

\section{intractable PC-BPPV. ${ }^{84}$}

Singular neurectomy, as described by Gacek in 1974, is an efficient procedure that was designed to control the symptoms of intractable BPPV, with an acceptable risk of postoperative hearing loss ${ }^{86}$ Canal occlusion and plugging are also effective techniques that are associated with a lower risk of hearing loss. ${ }^{85}$

However, surgical intervention should be waived until all CRMs/exercises have been attempted and failed. 


\section{Medical treatment}

Routine medications such as vestibular suppressants (e.g., antihistamine and benzodiazepine) are not recommended in BPPV patients. Clinicians may prescribe medications to either 1) reduce the spinning sensations of vertigo or 2) reduce the accompanying motion sickness symptoms. However, none of these vestibular suppressants is as effective as the CRMs for BPPV, and cannot be used as a substitute for the repositioning maneuvers. ${ }^{88,89}$

Antivertiginous drugs, such as dimenhydrinate (Dramamine $^{\circledR}$ ), the belladonna alkaloid scopolamine (Transderm$\operatorname{Scop}^{\circledR}$ ), and benzodiazepine $\left(\right.$ Valium $^{\circledR}$ ), are indicated for the symptomatic relief of dizziness and nausea before the execution of a CRM. ${ }^{90}$

\section{Prognosis and Recurrence}

Vertigo often recurs in BPPV, with reported recurrence rates of $15-37 \%$ after effective initial CRMs. ${ }^{2,11,91,92}$ In a recent study, the recurrence rate was $50 \%$ during a mean follow-up period of 10 years. ${ }^{93}$ Most recurrences $(80 \%)$ occur within the first year after treatment.

Factors associated with a higher recurrence rate include being female, ${ }^{93}$ presence of preceding illnesses such as trauma, labyrinthitis, and endolymphatic hydrops,${ }^{91}$ presence of osteopenia/osteoporosis, ${ }^{29} \mathrm{HC}-\mathrm{BPPV},{ }^{92}$ and a history of three or more BPPV attacks prior to treatment. ${ }^{93}$

\section{Conclusion}

BPPV is a very common disorder that causes paroxysms of positional vertigo. Even though BPPV is a benign disease that is treatable using relatively simple bedside maneuvers, a North American study reported the costs of BPPV to be more than US\$ 2,000 per individual, most of the expenses being attributable to inappropriate diagnostic procedures and ineffective therapies. ${ }^{94}$ Correct diagnosis and proper treatments based on current concepts of BPPV will reduce these unnecessary diagnostic procedures and costs.

\section{Conflicts of Interest}

The authors have no financial conflicts of interest.

\section{REFERENCES}

1. Hotson JR, Baloh RW. Acute vestibular syndrome. $N$ Engl J Med 1998;339:680-685.

2. Furman JM, Cass SP. Benign paroxysmal positional vertigo. $N$ Engl J Med 1999;341:1590-1596.

3. Bertholon P, Tringali S, Faye MB, Antoine JC, Martin C. Prospective study of positional nystagmus in 100 consecutive patients. Ann Otol Rhinol Laryngol 2006;115:587-594.

4. Steenerson RL, Cronin GW, Marbach PM. Effectiveness of treatment techniques in 923 cases of benign paroxysmal positional vertigo. $\mathrm{La}$ ryngoscope 2005;115:226-231.

5. Barany R. Diagnose von krankheitserscheinungen im. Bereiche des otolithenapparates. Acta Otolaryngol 1921;2:434-437.

6. Dix MR, Hallpike CS. The pathology symptomatology and diagnosis of certain common disorders of the vestibular system. Proc $R$ Soc Med 1952;45:341-354.

7. Schuknecht HF. Cupulolithiasis. Arch Otolaryngol 1969;90:765-778.

8. Hall SF, Ruby RR, McClure JA. The mechanics of benign paroxysmal vertigo. J Otolaryngol 1979;8:151-158.

9. Parnes LS, McClure JA. Free-floating endolymph particles: a new operative finding during posterior semicircular canal occlusion. Laryngoscope 1992;102:988-992.

10. Semont A, Freyss G, Vitte E. Curing the BPPV with a liberatory maneuver. Adv Otorhinolaryngol 1988;42:290-293.

11. Epley JM. The canalith repositioning procedure: for treatment of benign paroxysmal positional vertigo. Otolaryngol Head Neck Surg 1992;107:399-404.

12. McClure JA. Horizontal canal BPV. J Otolaryngol 1985;14:30-35.

13. Baloh RW, Yue Q, Jacobson KM, Honrubia V. Persistent directionchanging positional nystagmus: another variant of benign positional nystagmus? Neurology 1995;45:1297-1301.

14. Honrubia V, Baloh RW, Harris MR, Jacobson KM. Paroxysmal positional vertigo syndrome. Am J Otol 1999;20:465-470.

15. Schratzenstaller B, Wagner-Manslau C, Strasser G, Arnold W. Canalolithiasis of the superior semicircular canal: an anomaly in benign paroxysmal vertigo. Acta Otolaryngol 2005;125:1055-1062.

16. Blatt PJ, Georgakakis GA, Herdman SJ, Clendaniel RA, Tusa RJ. The effect of the canalith repositioning maneuver on resolving postural instability in patients with benign paroxysmal positional vertigo. Am J Otol 2000;21:356-363.

17. Giacomini PG, Alessandrini M, Magrini A. Long-term postural abnormalities in benign paroxysmal positional vertigo. ORL J Otorhinolaryngol Relat Spec 2002;64:237-241.

18. Baloh RW, Jacobson K, Honrubia V. Horizontal semicircular canal variant of benign positional vertigo. Neurology 1993;43:2542-2549.

19. Bhattacharyya N, Baugh RF, Orvidas L, Barrs D, Bronston LJ, Cass $\mathrm{S}$, et al. Clinical practice guideline: benign paroxysmal positional vertigo. Otolaryngol Head Neck Surg 2008;139:S47-S81.

20. von Brevern M, Radtke A, Lezius F, Feldmann M, Ziese T, Lempert T, et al. Epidemiology of benign paroxysmal positional vertigo: a population based study. J Neurol Neurosurg Psychiatry 2007;78:710-715.

21. Baloh RW, Honrubia V, Jacobson K. Benign positional vertigo: clinical and oculographic features in 240 cases. Neurology 1987;37:371-378.

22. von Brevern M, Seelig T, Neuhauser H, Lempert T. Benign paroxysmal positional vertigo predominantly affects the right labyrinth. $J$ Neurol Neurosurg Psychiatry 2004;75:1487-1488.

23. Parnes LS, Agrawal SK, Atlas J. Diagnosis and management of benign paroxysmal positional vertigo (BPPV). CMAJ 2003;169:681-693.

24. Moon SY, Kim JS, Kim BK, Kim JI, Lee H, Son SI, et al. Clinical characteristics of benign paroxysmal positional vertigo in Korea: a multicenter study. J Korean Med Sci 2006;21:539-543.

25. Nuti D, Mandalà M, Salerni L. Lateral canal paroxysmal positional vertigo revisited. Ann N Y Acad Sci 2009;1164:316-323.

26. Imai T, Ito M, Takeda N, Uno A, Matsunaga T, Sekine K, et al. Natural course of the remission of vertigo in patients with benign paroxysmal positional vertigo. Neurology 2005;64:920-921.

27. De la Meilleure G, Dehaene I, Depondt M, Damman W, Crevits L, Vanhooren G. Benign paroxysmal positional vertigo of the horizontal canal. J Neurol Neurosurg Psychiatry 1996;60:68-71.

28. Vibert D, Kompis M, Häusler R. Benign paroxysmal positional vertigo in older women may be related to osteoporosis and osteopenia. Ann Otol Rhinol Laryngol 2003;112:885-889.

29. Jeong SH, Choi SH, Kim JY, Koo JW, Kim HJ, Kim JS. Osteopenia and osteoporosis in idiopathic benign positional vertigo. Neurology 
2009;72:1069-1076.

30. Karlberg M, Hall K, Quickert N, Hinson J, Halmagyi GM. What inner ear diseases cause benign paroxysmal positional vertigo? Acta Otolaryngol 2000;120:380-385.

31. Gordon CR, Levite R, Joffe V, Gadoth N. Is posttraumatic benign paroxysmal positional vertigo different from the idiopathic form? Arch Neurol 2004;61:1590-1593.

32. Katsarkas A. Benign paroxysmal positional vertigo (BPPV): idiopathic versus post-traumatic. Acta Otolaryngol 1999;119:745-749.

33. Hong SL, Kim JS, Koo JW. A case of contralateral benign paroxysmal positional vertigo after mastoidectomy. J Korean Bal Soc 2005;4:45-48.

34. Kaplan DM, Attal U, Kraus M. Bilateral benign paroxysmal positional vertigo following a tooth implantation. J Laryngol Otol 2003; 117:312-313.

35. Ishiyama A, Jacobson KM, Baloh RW. Migraine and benign positional vertigo. Ann Otol Rhinol Laryngol 2000;109:377-380.

36. Cohen HS, Kimball KT, Stewart MG. Benign paroxysmal positional vertigo and comorbid conditions. ORL J Otorhinolaryngol Relat Spec 2004;66:11-15.

37. Ziavra NV, Bronstein AM. Is uric acid implicated in benign paroxysmal positional vertigo? J Neurol 2004;251:115.

38. Amor-Dorado JC, Llorca J, Costa-Ribas C, Garcia-Porrua C, Gonzalez-Gay MA. Giant cell arteritis: a new association with benign paroxysmal positional vertigo. Laryngoscope 2004;114:1420-1425.

39. von Brevern M, Schmidt T, Schönfeld U, Lempert T, Clarke AH. Utricular dysfunction in patients with benign paroxysmal positional vertigo. Otol Neurotol 2006;27:92-96.

40. Ushio M, Murofushi T, Iwasaki S. Subjective visual horizontal in patients with posterior canal benign paroxysmal positional vertigo. Acta Otolaryngol 2007;127:836-838.

41. Yang WS, Kim SH, Lee JD, Lee WS. Clinical significance of vestibular evoked myogenic potentials in benign paroxysmal positional vertigo. Otol Neurotol 2008;29:1162-1166.

42. Sugita-Kitajima A, Koizuka I. Recovery of otolith function in patients with benign paroxysmal positional vertigo evaluated by sinusoidal off-vertical axis rotation. Neurosci Lett 2008;436:124-127.

43. Otsuka K, Suzuki M, Furuya M. Model experiment of benign paroxysmal positional vertigo mechanism using the whole membranous labyrinth. Acta Otolaryngol 2003;123:515-518.

44. Humphriss RL, Baguley DM, Sparkes V, Peerman SE, Moffat DA. Contraindications to the Dix-Hallpike manoeuvre: a multidisciplinary review. Int J Audiol 2003;42:166-173.

45. Asprella Libonati G. Diagnostic and treatment strategy of lateral semicircular canal canalolithiasis. Acta Otorhinolaryngol Ital 2005; 25:277-283

46. Han BI, Oh HJ, Kim JS. Nystagmus while recumbent in horizontal canal benign paroxysmal positional vertigo. Neurology 2006;66:706710 .

47. Koo JW, Moon IJ, Shim WS, Moon SY, Kim JS. Value of lying-down nystagmus in the lateralization of horizontal semicircular canal benign paroxysmal positional vertigo. Otol Neurotol 2006;27:367-371.

48. Lee SH, Choi KD, Jeong SH, Oh YM, Koo JW, Kim JS. Nystagmus during neck flexion in the pitch plane in benign paroxysmal positional vertigo involving the horizontal canal. J Neurol Sci 2007;256:75-80.

49. Bisdorff AR, Debatisse D. Localizing signs in positional vertigo due to lateral canal cupulolithiasis. Neurology 2001;57:1085-1088.

50. Asprella-Libonati G. Pseudo-spontaneous nystagmus: a new sign to diagnose the affected side in lateral semicircular canal benign paroxysmal positional vertigo. Acta Otorhinolaryngol Ital 2008;28:73-78.

51. von Brevern M, Clarke AH, Lempert T. Continuous vertigo and spontaneous nystagmus due to canalolithiasis of the horizontal canal. Neurology 2001;56:684-686.

52. Lee SH, Kim MK, Cho KH, Kim JS. Reversal of initial positioning nystagmus in benign paroxysmal positional vertigo involving the horizontal canal. Ann N Y Acad Sci 2009;1164:406-408.
53. Brantberg K, Bergenius J. Treatment of anterior benign paroxysmal positional vertigo by canal plugging: a case report. Acta Otolaryngol 2002;122:28-30.

54. Zapala DA. Down-beating nystagmus in anterior canal benign paroxysmal positional vertigo. J Am Acad Audiol 2008;19:257-266.

55. Tomaz A, Ganança MM, Ganança CF, Ganança FF, Caovilla HH, Harker L. Benign paroxysmal positional vertigo: concomitant involvement of different semicircular canals. Ann Otol Rhinol Laryngol 2009;118:113-117.

56. Arai M, Terakawa I. Central paroxysmal positional vertigo. Neurology 2005;64:1284.

57. Kattah JC, Talkad AV, Wang DZ, Hsieh YH, Newman-Toker DE. HINTS to diagnose stroke in the acute vestibular syndrome: threestep bedside oculomotor examination more sensitive than early MRI diffusion-weighted imaging. Stroke 2009;40:3504-3510.

58. Bertholon P, Bronstein AM, Davies RA, Rudge P, Thilo KV. Positional down beating nystagmus in 50 patients: cerebellar disorders and possible anterior semicircular canalithiasis. J Neurol Neurosurg Psychiatry 2002;72:366-372.

59. Nam J, Kim S, Huh Y, Kim JS. Ageotropic central positional nystagmus in nodular infarction. Neurology 2009;73:1163.

60. Anagnostou E, Mandellos D, Limbitaki G, Papadimitriou A, Anastasopoulos D. Positional nystagmus and vertigo due to a solitary brachium conjunctivum plaque. J Neurol Neurosurg Psychiatry 2006;77: 790-792.

61. Seok JI, Lee HM, Yoo JH, Lee DK. Residual dizziness after successful repositioning treatment in patients with benign paroxysmal positional vertigo. J Clin Neurol 2008;4:107-110.

62. Brandt T, Daroff RB. Physical therapy for benign paroxysmal positional vertigo. Arch Otolaryngol 1980;106:484-485.

63. Sargent EW, Bankaitis AE, Hollenbeak CS, Currens JW. Mastoid oscillation in canalith repositioning for paroxysmal positional vertigo. Otol Neurotol 2001;22:205-209.

64. Macias JD, Ellensohn A, Massingale S, Gerkin R. Vibration with the canalith repositioning maneuver: a prospective randomized study to determine efficacy. Laryngoscope 2004;114:1011-1014.

65. Casqueiro JC, Ayala A, Monedero G. No more postural restrictions in posterior canal benign paroxysmal positional vertigo. Otol Neurotol 2008;29:706-709.

66. Hilton M, Pinder D. The Epley (canalith repositioning) manoeuvre for benign paroxysmal positional vertigo. Cochrane Database Syst Rev 2004:CD003162.

67. Oh HJ, Kim JS, Han BI, Lim JG. Predicting a successful treatment in posterior canal benign paroxysmal positional vertigo. Neurology 2007;68:1219-1222.

68. Fife TD, Iverson DJ, Lempert T, Furman JM, Baloh RW, Tusa RJ, et al. Practice parameter: therapies for benign paroxysmal positional vertigo (an evidence-based review): report of the Quality Standards Subcommittee of the American Academy of Neurology. Neurology 2008;70:2067-2074.

69. Salvinelli F, Trivelli M, Casale M, Firrisi L, Di Peco V, D’Ascanio L, et al. Treatment of benign positional vertigo in the elderly: a randomized trial. Laryngoscope 2004;114:827-831.

70. Radtke A, Neuhauser H, von Brevern M, Lempert T. A modified Epley's procedure for self-treatment of benign paroxysmal positional vertigo. Neurology 1999;53:1358-1360.

71. Radtke A, von Brevern M, Tiel-Wilck K, Mainz-Perchalla A, Neuhauser H, Lempert T. Self-treatment of benign paroxysmal positional vertigo: Semont maneuver vs Epley procedure. Neurology 2004;63: $150-152$.

72. Lempert T. Horizontal benign positional vertigo. Neurology 1994; 44:2213-2214.

73. Vannucchi P, Giannoni B, Pagnini P. Treatment of horizontal semicircular canal benign paroxysmal positional vertigo. J Vestib Res 1997; $7: 1-6$. 
74. Appiani GC, Catania G, Gagliardi M. A liberatory maneuver for the treatment of horizontal canal paroxysmal positional vertigo. Otol Neurotol 2001;22:66-69.

75. [Repositioning maneuver in benign paroxysmal vertigo of horizontal semicircular canal.] Acta Otorhinolaryngol Ital 1998;18:363-367.

76. Riggio F, Dispenza F, Gallina S, Kulamarva G, Gargano R, Speciale R. Management of benign paroxysmal positional vertigo of lateral semicircular canal by Gufoni's manoeuvre. Am J Otolaryngol 2009;30: 106-111.

77. Oh SY, Kim JS, Jeong SH, Oh YM, Choi KD, Kim BK, et al. Treatment of apogeotropic benign positional vertigo: comparison of therapeutic head-shaking and modified Semont maneuver. J Neurol 2009; 256:1330-1336.

78. Nuti D, Vannucchi P, Pagnini P. Benign paroxysmal positional vertigo of the horizontal canal: a form of canalolithiasis with variable clinical features. $J$ Vestib Res 1996;6:173-184.

79. Casani AP, Vannucci G, Fattori B, Berrettini S. The treatment of horizontal canal positional vertigo: our experience in 66 cases. Laryngoscope 2002;112:172-178.

80. Appiani GC, Catania G, Gagliardi M, Cuiuli G. Repositioning maneuver for the treatment of the apogeotropic variant of horizontal canal benign paroxysmal positional vertigo. Otol Neurotol 2005;26:257-260.

81. Crevits L. Treatment of anterior canal benign paroxysmal positional vertigo by a prolonged forced position procedure. J Neurol Neurosurg Psychiatry 2004;75:779-781.

82. Kim YK, Shin JE, Chung JW. The effect of canalith repositioning for anterior semicircular canal canalithiasis. ORL J Otorhinolaryngol Relat Spec 2005;67:56-60.

83. Norré ME. Rationale of rehabilitation treatment for vertigo. Am J Otolaryngol 1987;8:31-35.

84. Leveque M, Labrousse M, Seidermann L, Chays A. Surgical therapy in intractable benign paroxysmal positional vertigo. Otolaryngol Head
Neck Surg 2007;136:693-698.

85. Agrawal SK, Parnes LS. Human experience with canal plugging. Ann N Y Acad Sci 2001;942:300-305.

86. Pournaras I, Kos I, Guyot JP. Benign paroxysmal positional vertigo: a series of eight singular neurectomies. Acta Otolaryngol 2008;128: $5-8$.

87. Gacek RR. Transection of the posterior ampullary nerve for the relief of benign paroxysmal positional vertigo. Ann Otol Rhinol Laryngol 1974;83:596-605.

88. Hain TC, Uddin M. Pharmacological treatment of vertigo. CNS Drugs 2003;17:85-100.

89. Fujino A, Tokumasu K, Yosio S, Naganuma H, Yoneda S, Nakamura $\mathrm{K}$. Vestibular training for benign paroxysmal positional vertigo. Its efficacy in comparison with antivertigo drugs. Arch Otolaryngol Head Neck Surg 1994;120:497-504.

90. Brandt T, Zwergal A, Strupp M. Medical treatment of vestibular disorders. Expert Opin Pharmacother 2009;10:1537-1548.

91. Del Rio M, Arriaga MA. Benign positional vertigo: prognostic factors. Otolaryngol Head Neck Surg 2004;130:426-429.

92. Sakaida M, Takeuchi K, Ishinaga H, Adachi M, Majima Y. Long-term outcome of benign paroxysmal positional vertigo. Neurology 2003; 60:1532-1534.

93. Brandt T, Huppert D, Hecht J, Karch C, Strupp M. Benign paroxysmal positioning vertigo: a long-term follow-up (6-17 years) of 125 patients. Acta Otolaryngol 2006;126:160-163.

94. Li JC, Li CJ, Epley J, Weinberg L. Cost-effective management of benign positional vertigo using canalith repositioning. Otolaryngol Head Neck Surg 2000;122:334-339.

95. Bergenius J, Tomanovic T. Persistent geotropic nystagmus--a different kind of cupular pathology and its localizing signs. Acta Otolaryngol 2006;126:698-704. 